\title{
The Construction of Happiness School Paradigm in Nakhon Ratchasima Province, Thailand
}

\author{
Lamprai Muangkong * and Chaturong Thanaseelangkun
}

Nakhon Ratchasima Rajabhat University, Thailand

\begin{abstract}
The research's purposes were: to investigated factors and the paradigms construction of the Happiness School (HS.) in Nakhon Ratchasima Province. The research was using Modified Delphi technique. The target group were 17 experts in Nakhon Ratchasima Province. By mixed methodology between qualitative and quantitative research. The data collected by the documentary study, interviews and the questionnaire. The data analyzed by contents analyzing median and interquartile range. The research found that; HS. factors were: the happiness at students, staffs, school environment and the social and communities. The paradigms HS. constructing were according to the HS. factors. The process were: Happy student; individual student, closing follow up, learning participation and active presenting. Happy staff; good governance, school activity participation, collaborative promoting, constructing organizational culture. Happy School environment; school area to livable learnable, providing learning resource to support the student learning, school cultural climate providing. Happy social and community; participatory educational administration, organization collaborative promoting learning resource, school management reflecting.
\end{abstract}

Keywords: paradigms; happiness school; happiness school factors; Modified Delphi technique

\section{Introduction}

All human beings are seeking to try and pursue endless happiness. Obviously, if the person has what he wants, it will affect both the body and the mind. Until being finally satisfied and happy, or it could be said to be easier to understand that love, happiness, hate, suffering. In Buddhism, never taught to seek happiness but taught to see understand and find ways to end suffering which is true way to happiness. By classifying happiness into 2 levels: happiness from relying on external factors (Sami Suk) is a lasting unsustainable happiness perceive happiness from all 5 senses, whether happy from hearing the melodious sounds, seeing beautiful things, has smelled a fresh scent, try the delicious food taste, experience the touch of soft things. As for happiness without external factors arising from the awareness of the mind (Nirami Suk) happily from the mindfulness. with a mind that is meditation and the mind that is not struggling to seek out the five senses will lead to happiness caused by the calmness, cleanliness, light of the inner soul that is a happy, lasting and stable happiness. Therefore able to create and develop oneself, society and nation able to live happily in society (Silpemo, T., 2011, p. 2)

People development is the key to driving and developing the country. Especially the development of educational quality so that people have desirable characteristics as they want. In accordance with the National Education Act BE 2542, Section 6, specify the educational management in order to develop the Thai people to be a complete human body, mind, intellect, knowledge and virtue with ethics and culture in life. Can live happily with others. Section 24 (5), in organizing the learning process. Provide educational institutions to encourage teachers to be able to organize the atmosphere, learning media environment and facilitates learning to be learned and knowledgeable. Including being able to use research as part of the learning process. The instructors and learners may learn together from the instructional media and various types of academic resources.(Ministry of Education, 2010, p. 3)

From the report of the Department of Mental Health presented the current problems of teenagers. Reflecting the life in an unhappy society that causes the problems to both themselves and society. Found that the top 5 were: stress problems, love problems, sex problems, mental health problems and family problems. Which these 


\section{Methodology}

This research is a mixed research, including qualitative research and quantitative research by using Modified Delphi technique to study factors and paradigm construction of the happiness school. The research is divided into 2 steps as follows.

Step 1: Study factors of happiness school.

The researcher conducted two phases: Phase 1, analysis, synthesis of documents, concepts, theories and research related to the elements of the school of happiness. Phase 2, study of school with excellent practice the construction of happiness school to multi-case study in Nakhon Ratchasima Province. The target group is the school director. The tools used for data collection are the data analysis, interview form that are content analysis that synthesizes. The results of the study lead to a further study framework.

Step 2: Study the construction of happiness school paradigm in Nakhon Ratchasima Province.

The researcher used the Modified Delphi technique of 3 rounds. The target group is 17 experts in Nakhon Ratchasima province. Which is derived from the selection of purposive sampling. Including education administrators, educational officer and director of the school. In the first round, is the study factors of the happiness school, the second round, study to practice the construction of happiness school, and the third round is a confirmation the construction of happiness school paradigm. The tools used were the questionnaire interview form. Data analysis using content analysis and analysis of statistics such as median and interquartile range details in each round are as follows.

Round 1: Study factors of happiness school in Nakhon Ratchasima Province.

The researcher conducted an interview with the opinions of 17 experts using the content frame from the first step. With interview form and voice recorder data analysis using content analysis and synthesize the corresponding data used to create a question, a rating scale of 5 levels about the way to create the happiness school. Find quality research tools by presenting to 3 experts for further examination and suggestion before being used in research

Round 2: Study of ways to construction the happiness school in Nakhon Ratchasima Province.

The researcher questioned the opinions of 17 experts using the same target group. Questionnaires created in round 1, data analysis using statistical analysis such as median and inter-quartile range by considering the consistency of comments that lead to consensus and determine the median of 3.50 and above and the interquartile range of not more than 1.50. Summarize the data that has been drafted to create the happiness school in Nakhon Ratchasima Province.

Round 3: Confirmation the construction of happiness school paradigm in Nakhon Ratchasima Province.

The researcher conducted an inquiry on 17 experts' opinions using the same target group. By questionnaires of opinion, type, choice, reply, agree and disagree with additional suggestions. Data analysis uses statistical analysis of percentages. Consist of with the information from additional suggestions. Conclusion is complete the construction of happiness school paradigm in Nakhon Ratchasima Province. 


\section{Result}

1. Factors of the happiness school in Nakhon Ratchasima Province. By analyzing content from documents academic article and interviewing schools with excellent practices in 3 locations found that it consists of 4 factor: happy students, happy staff, happy school environment, happy social and communities

2. The construction of happiness school paradigm in Nakhon Ratchasima Province.

Consider each factors as follows :

\section{Happy students}

- Analysis (A1): Should analyze individual learners both knowledge life skills and experiences that will lead to student planning and development as well as the care system to help students continue.

- Attention (A2): By monitoring and closely monitoring students use beautiful words to talk and exchange in a friendly way to make students feel good and want to come to school.

- Active integration (A3): By teaching integrated opportunities for students to engage in learning activities get together to think, plan and propose activities according to creative interests. Accordance with the needs and aptitudes of the students. The activities are diverse and should be sufficient for all students. In addition, the students should cultivate a positive mind with events mental faculties to learn to live with themselves, know discipline duties and responsibilities both to themselves and others.

- Academic encourage (A4): By encouraging all learners to participate in expression in group activities. Encouraging learners to learn experiences from outside learning resources and promote occupational skills for future learners. Including organizing activities for students to appreciate and be proud of the success of their studies

\section{Happy staff}

- Good governance (G1): The executives are transparent in their work. Under good governance to lead to confidence and faith

- Give opportunity (G2): There are assignments according to individual aptitude and appropriate amount. Opportunity for teachers and personnel to participate in thinking participate in planning school activities. And participate in the benefit of educational management

- Generation learning (G3): Encourage the exchange of learning activities for both internal and external personnel. Have a team work process under supervision good close consultation of the management

- Good value (G4): There is an expression of respect and honor. Create prototype personnel to be able to transfer knowledge and work experience. Create morale in work by honoring good people. Until creating good values and leading to the corporate culture 


\section{Happy school environment}

- Livable (L1): There is an analysis of the school context to lead the development plan. Arrange the area to be clean, shady, beautiful, pleasant to look, pleasant to study, safe, free from odor and noise pollution.

- Learning center (L2): Improve school buildings and classrooms to be suitable according to the age of the learners. Provide facilities, technology and modern media as well as promoting a lively classroom atmosphere that creates a friendly atmosphere between teachers and students.

- Living relationship (L3): Greetings, beaming honor each other until a good relationship between the management, personnel, students and parents until the success of the job

\section{Happy social and communities}

- Participation network (P1): Opportunity for families and communities to participate in thinking plan and receive benefits in school activities in the form of a board of educational institution. There is a meeting to meet, discuss and express opinions for the development of education.

- Parent volunteer (P2): Promote cooperation with external agencies in support of learning resources. Create a network of organizations, agencies, both public and private sectors. In support of budget, education management and dissemination of academic knowledge and wisdom

- Personnel award (P3): Organize activities to reflect the school's performance at the end of the academic year. Organizing activities, honoring and honoring by giving awards to participants in educational management

From the research result to study the construction of happiness school paradigm in Nakhon Ratchasima Province. Can be summarized within model in figure.

\section{Happiness school paradigm model}

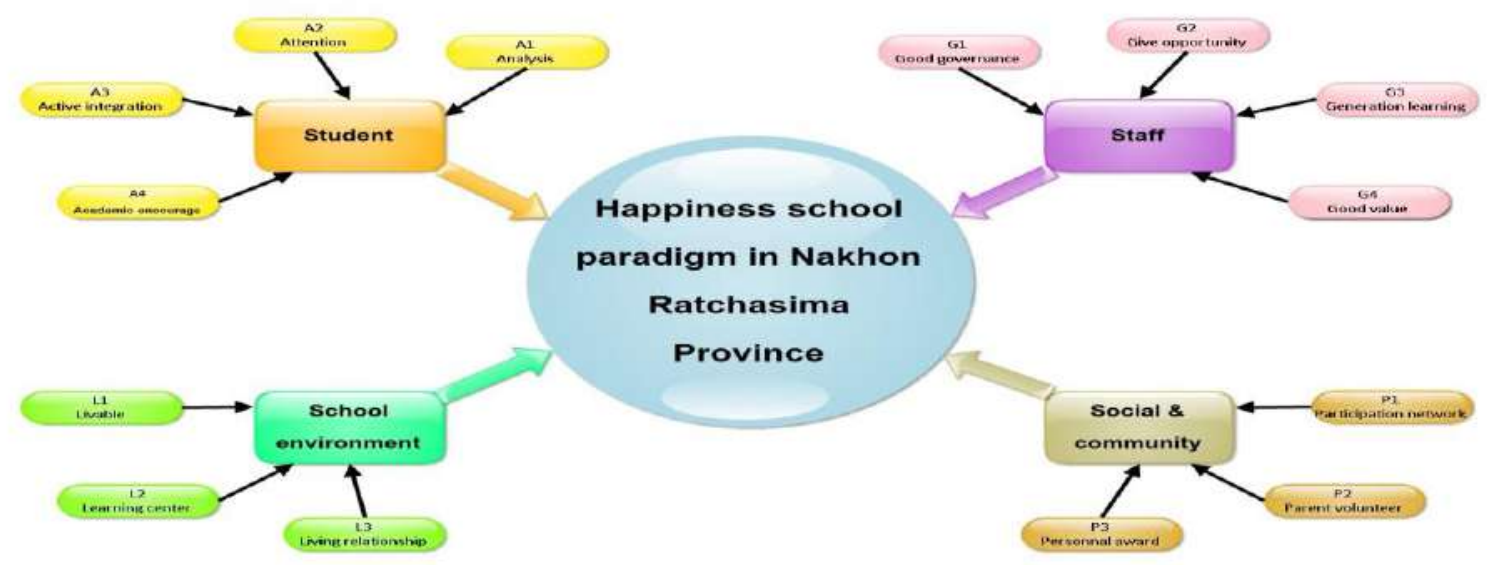

Figure 1:The happiness school paradigm model in Nakhon Ratchasima Province. 


\section{Discussion}

From the factors of the happiness school in Nakhon Ratchasima Province, in 4 aspects: happy students, happy staff, happy school environment, happy social and communities. It is both the basis and the important goal of education. Which the quality of learners is the goal of education management. Teachers and personnel are important people in driving missions and education management. If the environment is appropriate, it will make work and learning activities happy. Family and community is considered a supporting factor and is related to the various missions of the school. Consistent with the study of school of health in 5 aspects: happy learner, happy School, happy environment, happy family and a happy community (Thai Health Promotion Foundation, 2017). Happy student indicators are, being healthy have the skills to deny yourself from danger, be disciplined know your face is responsible, enthusiastic about learning, have a public mind, know the conservation of resources and the environment, can live happily with others.

From the construction of happiness school paradigm in Nakhon Ratchasima Province, in 4 aspects: happy students, happy staff, happy school environment, happy social and communities. Can discuss the results in each of the following factors.

\section{Happy students}

The guidelines that lead to the happiness of the learner. First, there should be individual student analysis. Both knowledge life skills and experiences that will lead to student planning and development as well as the care system to help students continue. Monitoring and closely monitoring students use beautiful words to talk and exchange in a friendly way to make students feel good and want to come to school. Teaching integrated opportunities for students to engage in learning activities get together to think, plan and propose activities according to creative interests. Accordance with the needs and aptitudes of the students. The activities are diverse and should be sufficient for all students. In addition, the students should cultivate a positive mind with events mental faculties to learn to live with themselves, know discipline duties and responsibilities both to themselves and others. Encouraging all learners to participate in expression in group activities, learners to learn experiences from outside learning resources and promote occupational skills for future learners. Including organizing activities for students to appreciate and be proud of the success of their studies. Consistent with the study the development of operational guidelines for health schools for educational institutions (Shamsheun, D., and Chomeya, R., 2017) should encourage learners to be able to communicate at least 2 languages. Organizing outside learning activities, both academic and professional in the future as well as activities that reflect the success of learners in order to create pride. It also consistent with the study of relationship between principals' creativity and degree of environmental happiness (Nader, S., and Elaheh, T., 2011) should know students individually, both skills talent things to develop. There is an allocation of hours for students to practice imagination and innovation of students. This may be due to the process will allow learners to see more of their own value from being accepted by others. Until being able to live happily in society

\section{Happy staff}

The guidelines that lead to the happiness of the staff. The executives are transparent in their work. Under good governance to lead to confidence and faith. Consistent with the study factors associated with happy workplace (Thongtanunam, Y., et al, 2015) executives should be a good role model for corporate both in practice the operation and treatment of others will lead to the acceptance of personnel. There are assignments according to individual aptitude and appropriate amount. Encourage the exchange of learning activities for both internal and external personnel. Have a team work process under supervision good close consultation of the management. Consistent with the study of the concept of personnel management within the organization (Happy Workplace 2010) In addition to the systematic operation of the organization. Importantly, there should be an assignment that is appropriate according to the potential of the person. Have good communication and mutual 
understanding. Listen to opinions and give opportunities for creative expression in the organization. There is an expression of respect and honor. Create prototype personnel to be able to transfer knowledge and work experience. Create morale in work by honoring good people. Until creating good values and leading to the corporate culture. This may be due to the process will make happy in their work and live together as a friendly person like a second home.

\section{Happy school environment}

The guidelines that lead to the happiness of the school environment. There is an analysis of the school context to lead the development plan. Arrange the area to be clean, shady, beautiful, pleasant to look, pleasant to study, safe, free from odor and noise pollution. Consistent with the study model of health development in primary schools (Chareonrak, K., et al, 2017). The first priority is to provide a healthy environment. Because they can see or touch clearly, especially the working atmosphere in the school that is conducive to learning and working together affecting the feelings of the person in a good way called "good atmosphere". Improve school buildings and classrooms to be suitable according to the age of the learners. Provide facilities, technology and modern media as well as promoting a lively classroom atmosphere that creates a friendly atmosphere between teachers and students. Greetings, beaming honor each other until a good relationship between the management, personnel, students and parents until the success of the job. Consistent with the study relationship between principals' creativity and degree of environmental happiness (Nader, S., and Elaheh, T., 2011). Adding lighting in the classroom, heating system, well designed and suitable cooling system, with the use of happy colors. This may be due to the process will makes the school interesting, has a good atmosphere leading to better motivation and contributing to effective learning.

\section{Happy social and communities}

The guidelines that lead to the happiness of the social and communities. Opportunity for families and communities to participate in thinking plan and receive benefits in school activities in the form of a board of educational institution. There is a meeting to meet, discuss and express opinions for the development of education. Promote cooperation with external agencies in support of learning resources. Create a network of organizations, agencies, both public and private sectors. In support of budget, education management and dissemination of academic knowledge and wisdom. Lessons have been taken to reflect the results of joint actions with the school board. Parent network village community network. Organize activities to reflect the school's performance at the end of the academic year. Organizing activities, honoring and honoring by giving awards to participants in educational management. Consistent with the study creating family and community participation in school health (Chareonrak, K., 2017). There should be a report of the results during the previous academic year for families and communities to be aware of the success of the work. This may be due to the process will expressing cooperation in educational management of all sectors in order to develop learners to meet the quality that families and communities need. It also Consistent with the study empowerment of educational management that creates health in schools (Erawan, P., 2014). Participation in the development of those involved in school both parents, family, community, school committee administrators and teachers considered to be a "school owner together". Have a plan for teamwork and sustainability and is aimed at learners.

In this research, the researcher conducted a review of every step from the opinions of experts. Together with the study from the operation process of the school with excellent practice. Therefore confirming that the paradigm of creating a school of happiness Nakhon Ratchasima is appropriate and possible in applying to the administration and education management for school reform to be quality 


\section{Recommendation}

1. From the results of the research, it was found that factors of happiness school consisted of 4 aspects: happy students, happy staffs, happy environment, happy social and community. Therefore, in formulating the school's strategic plan, it should be important to promote and develop all 4 factors on the basis of happiness schools should have a systematic policy and empirical activities that can be practiced in concrete ways. Especially the annual action plan that should be a plan for the implementation of various projects. To be consistent with all 4 factors in order to contribute to the development of being the happiness school.

2. There should be research to develop the happiness school model. So that schools can be used as guidelines for planning and development of further education. And participatory action research by bringing the creation happiness school paradigm into practice with schools with different context to see more diverse development approaches. As well as project-level research to enhance happiness and should be assessed project to monitor the operation continuously leading to sustainable development and driving towards becoming a school of happiness.

\section{References}

Chareonrak, K., et al, 2017, Health development model in elementary schools in the eastern region of North. Journal of Educational Administration Bua Bandit, 17(2), 441-453

Chareonrak, K., 2017, The creation of family and community participation in the health school. Academic Journal, 20(3), 2-15

Erawan, P., 2014, Empowerment of educational management that creates school health. Journal of Curriculum Research and Development, 4(1), 1-12

Happy Workplace, 2010, 9 organizations, 9 ideas. Nonthaburi: Prince Ozone Co., Ltd.

Ministry of Education, 2010, National Education Act BE 2542 (1999) as amended (No. 2) 2002 and as amended (No. 3) 2010. Bangkok: Goods and Parcel Delivery Organization Information Technology (ETO)

Ministry of Public Health, 2018, Date of access:20/5/2018.https://www.dmh.go.th/news$\mathrm{dmh} /$ view.asp?id=27571)

Nader, S., and Elaheh, T., 2011, A study of the relationship between principals' creativity and degree of environmental happiness in Semnan high schools. Procedia - Social and Behavioral Sciences, 29 (2011), 1869 1876

Office of Health Promotion Foundation, 2014, Why Thai teenagers Have emotional problems, Date of access: 11/7/2018. https://www.thaihealth.or.th/Content/19529

Shamsheun, D., and Chomeya, R., 2017, Developing the guidelines for the operation of the health school for schools. Under the Office of Primary Education Service Area, Udon Thani District 1. Journal of Educational Administration and Supervision, 8(1), 96 - 105

Silpaemo, T., 2011, A comparative study of the concept of Niramisuk in Theravada Buddhist philosophy and the concept of happiness based on popular wisdom. Unpublished Master of Buddhist Thesis, Mahachulalongkornrajavidyalaya University

Thai Health Promotion Foundation, 2017, School of Health New innovative study, Date of access: 11/5/2018. http://resource.thaihealth.or.th/library/hot/16637

Thongtanunam, Y., et al, 2015, Factors associated with happy workplace (public sector organization):

A systematic review. JOURNAL OF HEALTH SCIENCE RESEARCH, 9(1), 52-62

Wasanthanarat, C., and wutawatchaikaew, T., 2017, Happiness Organization 4.0. (2nd edition). Bangkok: At Four Print. 